\title{
TV/Series
}

14 | 2018

Posthumains en séries

\section{"Not much of a rind on you": (De)Constructing Genre and Gender in Westworld (Lisa Joy and Jonathan Nolan, HBO, 2016-)}

\section{Elizabeth Mullen}

\section{(2) OpenEdition \\ Journals \\ Édition électronique \\ URL : http://journals.openedition.org/tvseries/3304 \\ DOI : 10.4000/tvseries.3304 \\ ISSN : 2266-0909 \\ Éditeur \\ GRIC - Groupe de recherche Identités et Cultures}

Référence électronique

Elizabeth Mullen, "Not much of a rind on you": (De)Constructing Genre and Gender in Westworld (Lisa Joy and Jonathan Nolan, HBO, 2016-) », TV/Series [En ligne], 14 | 2018, mis en ligne le 31 décembre 2018, consulté le 19 avril 2019. URL : http://journals.openedition.org/tvseries/3304 ; DOI : 10.4000/ tvseries.3304

Ce document a été généré automatiquement le 19 avril 2019.

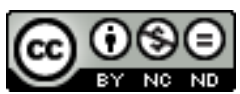

TV/Series est mis à disposition selon les termes de la licence Creative Commons Attribution - Pas d'Utilisation Commerciale - Pas de Modification 4.0 International. 


\title{
"Not much of a rind on you": (De)Constructing Genre and Gender in Westworld (Lisa Joy and Jonathan Nolan, HBO, 2016-)
}

\author{
Elizabeth Mullen
}

\section{Out of Metropolis and into the Uncanny Valley: Blurring Gender and Genre}

1 Pygmalion texts - where a male creator tries to build the perfect woman who then turns on him and causes chaos, only to be destroyed in the end - are hardly new to science fiction, nor is the figure of the male robot or cyborg intent on destruction something rare in cinema, television or video games. Where robots represent the Other and humans the norm, we often find narratives where the real "monsters" are not the ones produced on assembly lines, but rather the ones with beating hearts wrapped in human skin. Similarly, the Western genre is full of easily recognizable gender tropes: the one good man who stands up against evil (then usually rides away), the coldhearted desperado, the cowardly townsman who may or may not experience a burst of courage, the sweet homestead maiden or the saloon prostitute with the heart of gold.

Westworld intermingles all these tropes, but with a twist. By first filming robot "host" narrative arcs using familiar cinema techniques - drenched colors, swelling music, extreme high- and low-angle shots - the series places the viewer firmly in the uncanny valley, that space where clear boundaries between humans and robots dissolve, leaving a firm sense of dis-ease ${ }^{1}$. Viewers' engagement with the hosts and their constructed narratives mirrors that of certain human "guests", customers who pay exorbitant rates to interact with and take part in the hosts' predetermined narrative loops. In each episode, sequences alternate between story lines in the park and those in the labs of Westworld, thus unsettling viewers, catching them up by drawing attention to the constructed nature 
of their experience each time they allow themselves to get drawn into the park's narratives.

In more concrete terms, when the virginal homesteader's daughter and the hooker with a heart of gold are robots, repeatedly dumped off at the lab to be repaired, rebooted and sent back into the park, a blurring of gender and genre lines inevitably occurs.

This approach underscores two essential elements in the deconstruction of gender. First, we get a play-by-play demonstration of Butlerian performativity through the use of repetitive story loops intercut in such a way as to underscore the audience's awareness of them. Second, the minute examination of the workings of a created hegemonic space demonstrates Vertesi's view that "technology does not change a social environment but instead strengthens and enforces preexisting gender roles" ${ }^{2}$. Before exploring how Westworld articulates the interplay between hegemony, technology and gender, let us first take a closer look at how the repetition of the expression referenced in the title, "not much of a rind on you" is used to force viewers to see the underpinnings of the gendered interactions between hosts and humans.

5 Five minutes into the first episode of the series, Clementine ${ }^{3}$, a female host coded as a saloon prostitute, approaches a male host (Teddy), caresses his cheek and says, "You're new. Not much of a rind on you; I'll give you a discount" (S01E01, 05'50-05'58). Filmed in a two-shot, the characters are closely framed, the lighting is warm, and the expression on Clementine's face is open and tender. The next time we see Clementine, she is seated naked in front of two lab technicians in an underground laboratory. The bluish lighting and multiple glass panes create a cold, clinical atmosphere in direct contrast to the earlier scene. In this setting, her robotic nature is made clearly manifest, though her occasional expressions, filmed in close-up, create a certain confusion both in the viewer and in a female lab tech, who, on impulse, leans in and kisses her robot lips. A few minutes later, the opening narrative repeats and once again we hear Clementine say to Teddy, "You're new. Not much of a rind on you. I'll give you a discount" (S01E01, $\left.24^{\prime} 25-24^{\prime} 31\right)$. Slight variations in camera movement and vocal tone change the scene slightly, as does the viewer's increased knowledge of the predetermined nature of the narrative. Future repetitions of the same exchange, most notably in episode eight, lead to more and more complex understandings of both the exchanges and the expression itself.

The primary meaning of Clementine's catchphrase is that the person she is addressing is new to the place: green, not yet hardened. In other words, he (or in one instance, she) doesn't have much of a "rind", a callused surface. It is interesting that Clementine, a creature bearing the name of a fruit which also has a rind and who suffers repeated penetrations of this rind, should use this particular line to approach her clients, be they human or host. Tellingly, the Oxford English Dictionary also defines rind as either the skin of an animal or a person, or as an exterior or outer covering, a boundary. At first, Clementine's remarks suggest that in Westworld, it is possible for hosts to get beyond the rind, to uncover what is under that outer covering; yet, each repetition of the line (and of the narrative loop) undermines this premise, suggesting rather that underneath the surface lie only more layers of predetermined, constructed responses. Throughout the series, the interactions between hosts and guests underscore the ways in which gender is constructed not only for the robot hosts, but for humans as well: human guests are constantly encouraged, in the words of Maeve the robot Madam, to "be whoever the fuck [they] want," while at the same time the park managers carefully track each human/ robot interaction and guide guests along predetermined, gendered paths. On a larger 
scale, Westworld explores how notions of hegemony and gender are articulated within a specifically fictional context.

\section{Gender, hegemony and fictional texts in Westworld: Clementine}

7 In his study of white masculinity, masochism and contemporary American culture, Taking It Like a Man, David Savran points out how fictional texts can serve to articulate hegemony:

Indeed, fictional texts, I believe, are particularly important for the production of hegemony, representing sites at which a wide range of ideologies and values can be visualized, reaffirmed, and challenged ${ }^{4}$.

8 In the case of Westworld, fictional texts are multiplied: in addition to its ties to adapted texts (Michael Crichton's 1973 film and its subsequent iterations), the TV series itself operates as a fictional text, containing multiple fictional texts which explore hegemony most notably the park (or is it parks?) created for guests to live out their fantasies, but also the fictional texts (or "builds" - a term borrowed from gaming culture) implanted, altered and updated in the hosts. Hegemony is explored not only within each of these fictional texts but also through their interplay. We see this process at work with three of the female robots in Westworld, Clementine, Dolores and Maeve.

9 As already mentioned, Clementine, the rind-smelling, discount-offering prostitute, is an excellent example of the ways in which Joy and Nolan force the viewer to acknowledge the multiple fictional texts at work within Westworld. Utilized within the park narrative, in S01E07 she also becomes instrumentalized by the human female members of the Delos administration as a tool to question the hegemony of the park's male creator (Dr. Ford) and his assistant Bernard. It is interesting to note the way power is gendered in the exchange among the humans on one side of the glass and how Clementine's signature "not much of a rind on you" takes on a more menacing meaning in the scene (22'47-29'01).

10 At the beginning of the scene, the cameral lingers on a series of shots featuring cool lighting, shiny floors and glass walls. Once the main characters have taken their places, the camera cuts between shots of the characters at varying angles and distances and shots of their reflections in different panes of glass. Before the primary action of the scene (a faked demonstration of how Ford's recent alterations to hosts' codes has resulted in their retaining past memories and becoming violent), the interplay between image, dialogue and sound underscores the construction of hegemonic power relationships. In the opening exchange below, Ford and Bernard square off against Charlotte Hale and a silent Theresa Cullen:

FORD. Miss Hale. I was not aware that those of your insight needed any... more

reflection.

HALE. Dr. Ford. Always charming.

BERNARD. (turning to Ford) What is the meaning of this?

FORD. Apparently Miss Hale and Miss Cullen have a presentation for us.

BERNARD. What about?

FORD. (shrugs) 
11 Ford's use of the antiquated title "Miss" and his reference to Hale's appearance demonstrate his perception of patriarchal control, as do Bernard's outraged tone and his refusal to acknowledge Hale's presence when he calls into question the legitimacy of the interview itself. Hale's remark, "always charming," marks her attempt to present Ford as quaint and nonthreatening.

12 Camera and dialogue work together to distill the conflict apparent in the exchange; Ford's remark begins off-camera, while a medium shot shows Charlotte Hale, Executive Director of Delos Corporation, reflected on a glass wall as she brushes her hair to the side. (This gesture will be repeated by Clementine after smashing the human-coded host's head into the glass wall until it shatters). As Ford continues his remark, the camera cuts to a high-angle establishing shot of the glassed-in room where Ford approaches Hale from behind and she turns to face him. The others present are grouped in an upper corner of the shot, looking every bit like the cluster of spectators they are. Further, Ford and Hale are filmed at the center of an ovoid neon circle, suggesting the cyclical nature of the scene to unfold. Hale's reply is filmed in a more traditional medium shot-countershot, but again, the beginning of her reply begins off-camera. Bernard's arrival and subsequent query are filmed more dynamically in a lateral travelling shot coalescing into a two-shot of both men facing the camera, interspersed with close ups of Hale; Theresa Cullen (looking away) and Ford (smirking slightly).

13 This detailed description of the first thirty seconds of the scene emphasizes the exquisite level of gendered semiotic overlapping taking place, and it takes on further significance when, in the last thirty seconds of the scene, the pattern is repeated and reversed: closeups of Bernard and Ford are accompanied by remarks from Hale on and off camera, challenging Bernard to reveal anyone else involved and firing him when he does not. The high-angle establishing shot is repeated, but this time the neon circle frames both women as they face the men, backs turned to the crumpled bodies of clementine and the robot guest on the other side of the shattered glass wall.

Still, at the emotional heart of the scene lies the interaction between Clementine and her human-coded robot guest. In the first loop, after Theresa commands the guest to "wake her up," Clementine once again voices her now-familiar comment, "not much of a rind on you," only to be viciously attacked by the guest as the non-diegetic thrumming of the musical score accompanies rapid camera movement intercut with reaction shots of the humans on the other side of the glass. A bloodied and battered Clementine seems to appeal directly to the camera before freezing on command. Once she is reset, the scene plays again, but with differences not only in outcome but also in film technique. The camera focuses in close-up on Clementine's still-bloody face; her expression seems not blank but troubled. There is a slight catch in her voice as, once again, she murmurs "you're new: not much of a rind on you," but this time she avoids the guest's violent outburst, attacking him instead as the camera once again cuts from Clementine's rapid movement to reaction shots of the others. A train-like rhythm familiar to viewers from S01E01 interweaves itself with sounds from the first loop, intensifying the atmosphere and distinguishing this second iteration from the first. In the final moments of the demonstration, Clementine again looks directly at the camera from behind the glass, touches her mouth and hair, then prepares to launch herself at the human tech worker before being gunned down. 
This scene operates on many levels. The sudden unprovoked violence shocks the viewer; Clementine's short-lived revenge is cathartic but scripted, a calculated means to an end. It is worth noting as well that from the park's point of view, Clementine's appropriate response is the first one - that of victim. Rather than a shattering of the glass ceiling, the final shot here implies more of a shattering of the walls between female robot and human roles. While Hale and Cullen seem to get the upper hand in terms of power here, let us not forget that the season does not end well for either of them. Nonetheless, the sequence explores not only the deconstructive layering of fictional texts, but also the question of agency.

\section{Deconstructing Female Agency: Dolores's Path of Pain and the Limits of Maeve's Extreme Makeover}

16 The series repeatedly shows Dolores, the oldest host of the park, following paths others have set out for her: she quotes Shakespeare and Alice and Wonderland, she constantly repeats her signature phrase about, ironically, "choosing" to see the beauty in the world and of her life having a purpose, and she talks of how her path will lead her to love, to her future. Alternately, she is repeatedly shot, stabbed and raped, each time filled with the same disbelieving shock and horror. Additionally, throughout S01 we see Dolores being guided along various paths in and out of the park by a number of male figures, be they host, human or park showrunner. At various points in the series, viewers witness the literal construction of Dolores, both in terms of her behavior and expressions and her physical body. For example, in the opening shots of first episode of the series, off-camera a man's voice commands, "Bring her back on line," then instructs the seated, naked female figure to "lose the accent" before asking a series of questions about "the nature of [her] reality". As the dialogue continues in voiceover, the camera zooms in on the robot's face as a fly slowly crawls over the surface of her eye, underscoring Dolores's total lack of agency and the constructed nature of her existence.

Throughout Season One, viewers witness Dolores going through her saloon loop: the arrival in town, the can falling from her bag, ready to be picked up by Teddy, by William or by another guest in the park; the camera work remains lush, the colors warm. Viewers get caught up again and again in her narrative, tuning in week after week or bingeing in order to know what happens next; yet each layer of repetition forces the viewer (and, in a key scene, young William) to realize that the "path" Dolores is meant to follow is an algorithmic one.

Finally, in the opening scene of S01E10 ("The Bicameral Mind"), viewers again hear Dolores in voiceover as the camera zooms out from a close-up on her robotic head. As she repeats her "dream" speech, we see a pair of hands working to affix Dolores's rubbery skin to a metallic frame in what is surely her first iteration. Even as, in a Fight Clubreminiscent plot twist, Dolores (and the viewer) realizes that she has, in fact, been talking to herself the whole time and that her consciousness is at the heart of the "maze," Dolores's last act in S01E10 (reuniting with Teddy, shooting down Ford and the other human guests) is revealed to be yet another program, put in place by someone else. In other words, at the end of the day, in spite of all the pain and suffering the aptly-named Dolores has been through and the illusion of growing self-awareness witnessed throughout the first season, Dolores remains, above all, the sum of her constructed 
"parts" - both those that make up her physical being and the parts she has been led to play within the various fictional texts of the park (and the series).

Maeve Millay is, literally, another story. As a repurposed host whose initial narrative as a homestead mother to a young daughter keeps breaking through the surface of her current build as a saloon madam, Maeve is the first host made aware of her robotic state. Episode after episode we see her, with the help of her human assistant, Felix, altering her own code, quite literally reconstructing her personality and seemingly gaining agency over the narrative itself. While Dolores endures pain and emerges confused by the revelations it brings, Maeve actively seeks out pain (and the subsequent trip to the repair shop) so as to further her transformation. When confronted with nightmarish images and flashbacks from her past, Maeve uses the tools provided and creates ways to find meaning in the fragments, no matter the personal cost.

In S01E08, Joy and Nolan overtly expose the constructed nature of the narrative, from music on the player piano to the performative verbal cues Maeve gives to change the story (28'45-34'00). The scene opens with a close-up on the curled roll of the player piano as the opening bars of a piano version of Amy Winehouse's "Back to Black" begin to play. The saloon scene opens much as it has in previous loops, but this time Maeve is fully conscious of being in the narrative - so much so that when the bartender remarks that her tab is high, Maeve performatively effects a change in the script, announcing "No I don't believe it has. In fact, Maeve's tab was in such good standing, she deserved a token of gratitude." The camera zooms in on a slight spasm on the bartender's face before he smiles and offers her a drink on the house. The rest of the scene follows the same pattern: Maeve clears the bar by sending the new and improved clementine and the other girls off to take a groups of clients upstairs, then announcing that the bartender has to go to the back to water down more drinks. She directs the gunplay in the street to the tune of the waltz from Tchaikovsky's Swan Lake, then directs the desperados escape with the safe. Though she still experiences flashbacks and trace moments of pain, she survives the encounter with her consciousness intact.

Like Dolores, Maeve here follows a predictable story line, one she can control. At first she may seem to fulfill Sue Short's "fantasy of female perfectibility 5 " - this idea that she can alter her narrative by making alterations to herself. And yet, at the moment where she has, in fact, managed to escape, she cannot resist her coding as mother and gets off the train to find the daughter she knows is only a construction - a seemingly inevitable slide back into traditional female gender norms.

\section{Life without Limits? Hegemonic Masculinity and its Discontents}

On the surface, traditional codes of masculinity are respected in Westworld, both in and out of the park. Among the host population, cowboys, prospectors, sheriffs and outlaws all adhere to genre and gender codes. This adherence does not spare male robots from objectification at the hands of guests and the occasional Delos worker, as we can see with Teddy, Hector and even Bernard. Additionally, many of the male hosts' prime directives center on traditional masculine roles. Peter Abernathy, for instance, is so strongly coded to protect his daughter Dolores that when trace elements of his past experiences begin to surface, they destroy him. Similarly, Teddy Flood's core drive (in the first episodes, 
vaguely to "take care of some things" before he can settle down with Dolores, then after an upgrade to seek revenge against the mysterious Wyatt) is so grossly stereotypical to the masculine Western genre as to be comical. The one apparent exception to this rule is Bernard, though even he takes umbrage at seeing his authority challenged.

Among the humans, Dr. Ford, the Godlike creator of this world, acts as a classic puppet master, pulling on various narrative strings throughout the season, showing at every turn that he is in control, that he is master of his universe, including the way in which he decides to blow it all up. Even his apparent conferring of free will upon Dolores smacks of religious overtones.

Still, two striking characteristics persist. While in the instance of Logan, there is a kind of gleeful embracing of the hegemony conferred upon him in the park - and his remarks to the effect that the guests are Gods underscore this view - for the most part non-robot masculinity in Delos can be coded in Kimmelian terms: a sense of dissatisfaction, of being cheated. Kimmel points out this paradox in Manhood in America:

How did the chronic restlessness of nineteenth century self-made man, which became the general malaise and discontent of twentieth-century masculinity, morph into the explosive rage of the twenty-first century? For one thing, the very adherence to traditional ideals of masculinity now leaves so many of them feeling cheated, unhappy, and unfulfilled.

American white men bought the promise of self-made masculinity, but its foundation had all but eroded. Instead of questioning those ideals, they fall back upon those same traditional notions of manhood - physical strength, self-control, power - that defined their fathers' and their grandfathers' eras, as if the solution to their problems were simply "more" masculinity ${ }^{6}$.

In short, despite its futuristic, science fictional setting and unlimited imaginative possibilities, we find here an echo of Schulman's Generation of Seekers (omnipresent in the 1970s) in a more toxic strain ${ }^{7}$. The Man in Black's unrelenting quest for the secret of the Maze is an example of this.

Much has been made of the hegemony of the Man in Black as an ultimate figure of evil, from his cruelty to his sadism. We might notice, however, the weary way he goes about his debauchery - despite his racial, gender, and financial hegemony, he feels tricked by the game precisely because it is rigged in his favor. To a lesser extent, ridiculous human male characters like Sizemore the ineffectual narrative creator and Sylvester the schlubby white computer tech seem to buy into gendered hegemonic systems even as they refuse to confer upon them the power they think they deserve. Note for instance how Rachel Hale instrumentalizes Sizemore's turning the acceptance of his new narrative into a literal pissing contest (when it is refused by Ford, he gets drunk and urinates all over the model of the park) in order to turn Sizemore into her puppet. Note also the exchanges between Sylvester and Maeve where he attempts to explain why she is trapped in her coding (without seemingly realizing he's equally trapped in his). Interestingly, masculine gender norms are most challenged by figures of color: Arnold/Bernard and Asian-featured Felix, the lab tech who helps Maeve reprogram herself. Maeve remarks on this difference when she says to Felix, "You make a terrible human. I mean that as a compliment."

Westworld's discourse on performing gender and performing (post)humanity at the diegetic level is echoed reflexively by the series' hybrid performance of genre 
, through the hybridization of western and sci-fi, but also, of serial storytelling and narrative progression of video games.

\section{Gaming the System: Gender, Production and Reception} choices whose influence will depend on viewers' own film and television experiences. To mention just a few: Anthony Hopkins, as Dr. Robert Ford, is instantly recognizable both as an authoritarian patriarchal figure (he plays Odin, after all, in the most recent series of Thors, not to mention Van Helsing in Coppola's 1992 Dracula, Nixon in Oliver Stone's 1995 film, Nixon and Hitchcock in Sacha Gervasi's 2012 biopic) and as an elegant, controlling monster (think of Silence of the Lambs). Thus, when viewers see him as the shadowy patriarchal God figure in Westworld, it resonates with memories of him in those other roles.

31 The same can be said of Thandie Newton (Maeve) previously seen in Crash (Paul Haggis, 2004) and Beloved (Jonathan Demme, 1998), both films where questions of race and gender intersect, and in Rogue (Audience Network, 2013-2017), a British-Canadian crime drama in which Newton plays an undercover cop plagued by the death of her child. Jeffrey Wright (Bernard/Arnold) is known to many as the far-from-manly Beetee from The Hunger Games franchise and as shady underworld figure Valentin Narcisse from HBO's Boardwalk Empire (2010-2014). Lastly, Theresa Cullen is played by Sidse Babett Knudsen, famous for her 
starring role in the Danish hit series Borgen (DRI, 2010-2013). Similar associations can be made for each character, and for some viewers it becomes a kind of game to figure out these links.

As Richard Dyer aptly points out, "A star image is made out of media texts that can be grouped together as promotion, publicity, films and criticism and commentaries ${ }^{9 "}$. Processing the interplay between these media texts, interactive reception thrives in thousands of fan-based blogs, Youtube videos, twitter feeds, Reddit threads and other participatory sites on top of all the web-based promotional materials generated by HBO and the entertainment industry. It is in these spaces that the work of constructing and deconstructing gender in Westworld (and in other media texts) can take place.

\section{Conclusion}

Through its aesthetic and production choices, incorporating star personae and gaming techniques as well as knowledge of western and science fiction genres, Westworld draws attention to the ways in which gender is consciously constructed and reinforced, both for the hosts and for humans. By analyzing specific scenes and exploring their interplay with character construction and world building through the prism of gender, it is possible to expose the working of gender construction in the series (across a variety of fictional texts that it echoes and reframes). Thus, by pulling apart the layered workings of the "rind" of gender and genre, we can begin to see the maze at the heart of Westworld for what it truly is: another layer to deconstruct within a variety of cultural frameworks.

\section{NOTES}

1. For a more in-depth exploration of the Uncanny Valley, see Shenseng Wang, Scott Lilienfield and Philippe Rochat, "The Uncanny Valley: Existence and Explanations", Review of General Psychology 19.4 (2015), p. 393-407.

2. Janet Vertesi, “Pygmalion's Legacy: Cyborg Women in Science Fiction" in SciFi in the Mind's Eye: Reading Science through Science Fiction, Ed. Margaret Grabowicz, Chicago, Open Court, 2007, p. 83.

3. The name Clementine has distinct resonances within the Western genre, of course - most notably the 19th-century traditional ballad (wherein Clementine comes to a tragic end) and John Ford's 1946 classic My Darling Clementine (in which Clementine is pursued by Wyatt Earp).

4. David Savran, Taking it Like a Man: White Masculinity, Masochism, and Contemporary American Culture, Princeton, Princeton University Press, 1998, p. 7.

5. Sue Short, Cyborg Cinema and Contemporary Subjectivity, New York, Palgrave-Macmillan, 2005, p. 88.

6. Michael Kimmel, Manhood in America: a Cultural History, New York, Oxford University Press, 2006, p. 218.

7. Bruce Schulman, The Seventies: The Great Shift in American Culture, Society, and Politics, Cambridge, Da Capo Press, 2001, p. 99. 
8. See the Reddit thread, What's in a Name: Maeve Millay first posted by $\mathrm{u} /$ Bobilon in September 2018, https://www.reddit.com/r/westworld/comments/99fz01/

whats_in_a_name_maeve_millay/,consulted December 26, 2018.

9. Richard Dyer, Stars, London, BFI, 1998, p. 60.

\section{RÉSUMÉS}

Cet article propose un exploration du brouillage des frontières génériques et genrées dans la série Westworld, créant ainsi des resonances qui déconstruisent les normes traditionnelles du genre. Par une analyse détaillée de certaines sequences clés de la première saison, cet article examine la construction du genre opérée par les robots et par les humains, à l'intérieur et à l'extérieur du parc avant d'explorer les questions de l'hégémonie masculine et de l'agentivité feminine à l'intérieur de ces mondes. Enfin, l'article s'attache au rôle joué par la production télévisuelle et la réception par les fans dans la création d'un contexte intertextuel qui a une incidence sur la construction des genres.

This article explores the ways in which the TV series Westworld blurs gender and genre, creating resonances that deconstruct traditional notions of gender roles. Through a minute analysis of several key scenes in the first season, it examines how robots and humans construct gender both within the park and without, and then explores the question of masculine hegemony and feminine agency within those worlds. Finally, the article undertakes to point out how production and reception interact to create intertextual frameworks that can shed light on questions of gender construction.

\section{INDEX}

Keywords : Westworld, masculinity, gender, Butler Judith, western, reception, science fiction, intertextuality, Dyer Richard, star

Mots-clés : Westworld, masculinité, réception, science-fiction, western, genre, Butler Judith, intertextualité, Dyer Richard, performance

\section{AUTEUR}

\section{ELIZABETH MULLEN}

Elizabeth Mullen is an Associate Professor at the Université de Bretagne Occidentale in Brest, France, where she is a member of HCTI, a research group dedicated to exploring text and image. She has published articles on The Shining, Deliverance and The Haunting of Hill House, and her recent work has focused on gender and the grotesque in film and television, especially the interplay between production, reception and aesthetic analysis.

Elizabeth Mullen est Maîtresse de conférences à l'Université de Bretagne Occidentale à Brest et membre d'HCTI, EA4249 spécialisée sur les rapports Texte/Image. Elle a publié des articles sur The Shining, Deliverance et The Haunting of Hill House. Ses travaux les plus récents se penchent sur 
la question du genre et du grotesque dans les arts visuels (films et télévision), et sur les interactions entre la production, la réception et l'analyse esthétique. 